\title{
Characteristics of Community Members who Recycle Household Hazardous Waste
}

\author{
By Chardon V. McCoy* \\ Mildred Naquin* \\ Ephraim Massawe \\ Wynn Gillan ${ }^{\dagger}$ \\ Caitlyn Haynes ${ }^{+}$ \\ Corinne Cormier \\ Marie Zannis"
}

\begin{abstract}
Household hazardous waste (HHW) continues to be a growing problem in the United States of America (USA), and globally. Disposing of HHW is important when protecting human health and the environment. Recycling HHW has many benefits including reducing contact with hazardous pollutants. This study describes participants in a HHW recycling program in a small southern community in the USA, and factors that influence their participation. This HHW Recycling Day collects (potentially) harmful substances from citizens for proper disposal. A 28 item questionnaire was completed by 145 participants. The top hazardous items recycled were paint, electronic waste, and batteries. Individuals who were retired were more likely to recycle and felt more confident about properly managing HHW. Men and participants with a college degree were more likely to recycle HHW. Educating the public regarding HHW disposal is essential. Funding such programs may increase community awareness.
\end{abstract}

Keywords: Pollution, Recycling attitudes, Recycling behaviors, Recycling habits, Residential waste.

\section{Introduction}

In the United States of America (USA), both natural and man-made chemicals play a part in our everyday lives. Chemicals are used to create most of the items we use daily, including household cleaning items, furniture, clothing, and electronic products such as computers, televisions, and cell phones. In fact, almost all products imaginable have some type of chemical(s) in them. When used correctly, human beings usually benefit from these products. However, when these chemicals are misused, they can become harmful, negatively impacting humans and the earth, affecting the waters, plants and land. Because

\footnotetext{
${ }^{*}$ Health Educator, Southeastern Louisiana University, USA.

* Professor, Southeastern Louisiana University, USA.

* Associate Professor, Southeastern Louisiana University, USA.

${ }^{\dagger}$ Assistant Professor, Southeastern Louisiana University, USA.

${ }^{+}$Health Educator, Southeastern Louisiana University, USA.

Graduate Assistant, Southeastern Louisiana University, USA.

- Health Educator, Nicholls State University - Thibodaux, Louisiana, USA.
} 
of their physical and chemical properties, substances such as batteries, pesticides, and by-products of televisions and cell phones when disposed of incorrectly become hazardous waste (United States Environmental Protection Agency [EPA] 2011). This household hazardous waste (HHW) may ultimately threaten the health of people and contaminate the environment.

Substances are determined to be hazardous waste by their effects or characteristics which are described as corrosive, ignitable, reactive, or toxic (EPA 2011, EPA 2013) all of which can cause human health and safety concerns as well as harmful effects on the environment. Once hazardous wastes are released into the environment, they can spread throughout the biosphere causing harm to surroundings whether they are persons, animals or plants. There are many different ways hazardous waste can harm the environment. The negative effects on human beings' exposure are determined by the type of substance, the duration of exposure, and concentration of the chemical, and ultimately the dose. How an individual is exposed to a chemical also plays a role in how it affects a person's health. In addition, individuals' susceptibility varies based on age, race, and gender. There are four main ways a person can be exposed to hazardous waste: inhalation, ingestion, injection and/or by physical contact (EPA 2011, National Institutes of Health [NIH] 2012).

Since hazardous substances are detrimental to the environment and living organisms, it is important to handle these substances properly while using them and also to dispose of them correctly. For example if not disposed of properly, heavy metals such as lead, cadmium, and mercury can get into the water supply and cause poisoning in living organisms. Certain heavy metals predominantly found in some HHW can also cause respiratory problems from air emissions and can contaminate soil impacting crops, water, trees, and flowers. It is critical to know how various types of hazardous substances need to be recycled. Hazardous substances that should be recycled include batteries, mercury thermometers, florescent light bulbs, and electronics (also called ewastes) (EPA 2013, Massawe et al. 2014).

Internationally, over a billion tons of municipal waste are generated annually, resulting in a worldwide average of 2.65 pounds $(1.2 \mathrm{~kg})$ per person, although the amount of waste varies by region (Hoornweg and Bhada-Tata 2012). According to the US Environmental Protection Agency (2014b), Americans produced around 251 million tons of trash in 2012 including hazardous substances. Of the waste produced, only 87 million tons $(34.5 \%)$ were recycled or composted. The average American individually produces about 4.38 pounds $(1.99 \mathrm{~kg})$ of waste every day in which only about a pound and-a-half is recycled or composted (EPA 2014b).

In the State of Louisiana (USA), the Louisiana Department of Environmental Quality (LDEQ) estimates that the total amount of commercial and residential solid waste generated and disposed of is close to five million wet-tons a year (2011). This number is reported from disposal facilities within Louisiana. The total amount of waste generated in Louisiana but disposed of outside of the state is unknown. As stated in the 2011 (LDEQ) Annual Report, there are 25 operating landfills in the State of Louisiana that accept municipal waste. 
Recycling hazardous wastes helps to prevent hazardous pollution, promote environmental health and conserve scarce resources such as precious metals. By reducing pollutants which are in the air, water and soil, hazardous waste recycling can prevent harmful effects on the environment. Recycling also reprocesses resources and energy for later use in generating more products. Reusing some hazardous substances or using them to remanufacture useful products decreases the need for producing more hazardous substances, thus helping to save money and reduce pollutants (EPA 2014a).

Household hazardous waste continues to grow in Louisiana, challenging cities to encourage residents to recycle municipal solid wastes. In the 2012 Annual Summary Report, the Louisiana Department of Environmental Quality reported there was a total of 2,222 tons of household hazardous waste recycled. This excludes household hazardous liquids ( 865 tons), electronic waste (468 tons), and lead acid batteries (5,586 tons). Annual municipal waste has decreased, suggesting that more household hazardous waste is being recycled (LDEQ 2013).

Many cities in the US have programs to collect hazardous waste from its citizens. One such program is the Household Hazardous Waste Recycling Day (HHWRD). The goal of the HHWRD program in Hammond, Louisiana is to address the growing need for recycling hazardous waste and to motivate its residents to become more active in recycling. The purpose of this study was to describe who participates in the HHWRD recycling program and to determine factors that influence participation.

\section{Method}

A questionnaire was constructed to gather information about the community's participation in the Household Hazardous Waste Recycling Day event in Hammond, Louisiana (USA). The 28-item questionnaire included 11 demographic questions about gender, race, age, marital status, employment, family income, and level of education. The questionnaire also asked participants how they learned about the Household Hazardous Waste Recycling Day event and how many times they had participated in the event. Other questions solicited information about the types of hazardous waste participants dispose of during the event and how they dispose of the substances that are not accepted at the event. In addition, participants were asked to select the reason(s) they were motivated to recycle hazardous waste.

Faculty members of the Kinesiology and Health Studies Department at a university in southeastern Louisiana (USA) as well as the Hammond (Louisiana) Storm Water Administration (HSWA) committee members reviewed the questionnaire. The hazardous waste recycling program was developed by the HSWA in the year 2000. Its purpose is to engage the residents of Hammond, Louisiana (USA) by increasing their hazardous waste disposal which also helps keep the city clean. The HSWA committee's review of the questionnaire was required since it oversees recycling events in the city.

During the process of validating the questionnaire, three undergraduate students from the university answered the questionnaire to help approximate the 
amount of time needed to complete the questionnaire. Furthermore, the study and the questionnaire were approved by the university's Institutional Review Board (IRB). A consent form which was included with the questionnaire informed the participants of the importance of the study and that their participation was voluntary. It also assured that only five minutes were needed to complete the questionnaire.

The consent form and the questionnaire were handed to participants during the collection time at the recycling project Household Hazardous Waste Recycling Day, which took place at a local park. This recycling project gives residents of Hammond, LA as well as surrounding cities an opportunity to recycle and dispose of any hazardous waste they may have. Participants were given the questionnaire upon entering the park, before they delivered the hazardous wastes. The questionnaires were then collected as the participants exited the park. Upon receiving the questionnaire, participants were given the purpose of the study and were assured that participation was voluntary and anonymous. Participants had the choice of completing the questionnaire on site or mailing the questionnaire to the principal investigator in the Department of Computer and Industrial Technology at the university.

\section{Participants}

Over 360 people participated in the Household Hazardous Waste recycling event. Of those who participated in the event, 145 completed a questionnaire for a response rate of $40 \%$. Of those who responded, $57.7 \% \quad(n=71)$ identified themselves as males and $42.3 \%(n=52)$ females. The majority of the participants, $75.7 \%(\mathrm{n}=100)$, were in the $40-70$ age range. Within that age range, about $60 \%$ $(n=53)$ identified themselves as males and about $40 \%(n=36)$ females. Only about $7 \%(n=9)$ of those who participated were in the 20-29 age range. Age of the participants was collected in four categories (Table 1).

The majority of the participants identified themselves as being married $(79.2 \%, \mathrm{n}=103)$ (Table 1). While evaluating the findings, marital status was collapsed or combined into two categories from four with the intent to determine possible statistical significance. The categories "married" and "separated" were collapsed into one category, "married". This group represents those participants who are legally married in the State of Louisiana, since the term "separated" still is legally considered as being married. The categories "single" and "committed relationship" was collapsed into one category, "single". This group represents those participants who are not legally married in the State of Louisiana. According to the findings, $90 \%(\mathrm{n}=61)$ of men were more likely to be married compared to $60 \%(n=29)$ of women $\left(X^{2}=13.9, \mathrm{df}=1, \mathrm{p}=0.000\right)$.

Reported family income of the participants ranged from under $\$ 25,000$ to over $\$ 150,000$ annually. The largest grouping of the participants $(23.5 \%, n=27)$ reported their annual family income as in the $\$ 25,000-\$ 39,999$ range. Twenty percent $(n=23)$ of participants reported that their family income was in the $\$ 50,000$ - \$74,999 range. The remaining income levels were distributed throughout the other six income categories (Table 1). 
Table 1. Demographic Information

\begin{tabular}{|c|c|c|}
\hline & $n$ & $\%$ \\
\hline \multicolumn{3}{|l|}{ Gender } \\
\hline Male & 71 & 57.7 \\
\hline Female & 52 & 42.3 \\
\hline \multicolumn{3}{|l|}{ Age } \\
\hline $20-39$ & 9 & 6.8 \\
\hline $40-59$ & 46 & 34.8 \\
\hline $60-70$ & 54 & 40.9 \\
\hline$>70$ & 23 & 17.4 \\
\hline \multicolumn{3}{|l|}{ Marital Status } \\
\hline Single & 27 & 20.8 \\
\hline Married & 103 & 79.2 \\
\hline \multicolumn{3}{|l|}{ Family Income (2010) } \\
\hline Under $\$ 25,000$ & 8 & 7.0 \\
\hline$\$ 25,000-\$ 39,999$ & 27 & 23.5 \\
\hline$\$ 40,000-\$ 49,999$ & 14 & 12.2 \\
\hline$\$ 50,000-\$ 74,999$ & 23 & 20.0 \\
\hline$\$ 75,000-\$ 99,999$ & 20 & 17.4 \\
\hline$\$ 100,000-\$ 124,999$ & 11 & 9.6 \\
\hline$\$ 125,000-\$ 149,999$ & 5 & 4.3 \\
\hline Over $\$ 150,000$ & 7 & 6.1 \\
\hline
\end{tabular}

Source: Authors' calculations.

As shown in Table 2, the majority of the participants reported having at least some college education. The largest percentage of participants reported having a bachelor's degree $(36.6 \%, n=45)$. About $46 \%(n=23)$ of those having a bachelor's degree identified themselves as females and about 27\% $(n=18)$ identified themselves as males. For further exploration, education level was combined or collapsed into two categories from the seven categories for statistical analysis. Those who had a college degree were combined into one category and those who did not have a degree were combined into the second one. About $59 \%(n=65)$ of those who participated in the HHWRD event had a college degree and about $41 \%$ $(n=45)$ of participants did not have a college degree.

Table 2. Education Level

\begin{tabular}{|c|c|c|}
\hline Education & $\boldsymbol{n}$ & $\mathbf{\%}$ \\
\hline Some High School & 2 & 1.6 \\
\hline High School Degree/ Equivalency & 21 & 17.1 \\
\hline Some College & 27 & 22.0 \\
\hline Associate Degree & 8 & 6.5 \\
\hline Bachelors Degree & 45 & 36.6 \\
\hline Masters Degree & 12 & 9.8 \\
\hline PhD College Degree & 8 & 6.5 \\
\hline
\end{tabular}

Source: Authors' calculations.

The majority of people who participated in the event were either retired $(49.2 \%, \mathrm{n}=62)$ or worked full time $(40.5 \%, \mathrm{n}=51)$. Other participants worked 
part time $(4.8 \%, \mathrm{n}=6)$, were unemployed $(3.2 \%, \mathrm{n}=4)$, or were students $(2.4 \%$, $\mathrm{n}=3$ ) (Table 3). Individuals who are retired or work full time may accumulate more hazardous substances since they may have a higher income than a part time worker or someone who is unemployed.

Table 3. Employment Status

\begin{tabular}{|c|c|c|}
\hline Employment & $\boldsymbol{n}$ & \% \\
\hline Full-time & 51 & 40.5 \\
\hline Part-time & 6 & 4.8 \\
\hline Unemployed & 4 & 3.2 \\
\hline Full-time student and employed & 2 & 1.6 \\
\hline Full- time student and unemployed & 1 & 0.8 \\
\hline Retired & 62 & 49.2 \\
\hline
\end{tabular}

Source: Authors' calculations.

For further exploration, employment was collapsed or combined into two categories from the six categories for statistical analyses. All of the participants who worked whether full time or part time were collapsed into one category, identified as "employed". Those who were unemployed and retired were collapsed into one category identified as "retired". About 52\% $(n=59)$ of the participants were identified as "retired" and about $48 \%(\mathrm{n}=54)$ were identified as employed. Of the male participants, equal numbers $(50 \%$; $n=33)$ identified themselves as being retired or employed. Approximately $55 \%(n=26)$ of the female participants were retired and $45 \%(n=21)$ were employed. There was no statistically significant difference in employment status by gender.

\section{Results and Discussion}

The top five household hazardous substances that were brought in by participants during this event were paint, electronic waste, batteries, light bulbs, and automotive waste. The top three substances that residences of the City of Hammond and surrounding areas disposed of were paint (68.8\%), electronic waste (54.2\%), and batteries (53.5\%) (Table 4). Findings also indicated that about 35\% $(n=25)$ of men were more likely to dispose of tires at the event than women $\left(X^{2}=7.4, \mathrm{df}=1, \mathrm{p}=0.005\right)$. Only about $14 \%(\mathrm{n}=7)$ of women disposed of tires during this recycling event. Men may be more likely to manage and collect tires from lawnmowers, cars, bicycles and other sources. They may be more experienced with changing tires, as men in a household may be more likely to customarily assume such duties, and are more knowledgeable about how hazardous tires are to the environment. This may suggest why men would be more likely to dispose of tires at the event. However, women may leave old tires to be disposed of where they purchase new ones.

We also found that participants who did not have a degree $(86 \%, \mathrm{n}=43)$ were more likely to bring in paint than those who had a degree $(61 \%, n=45)\left(X^{2}=8.6\right.$, $\mathrm{df}=1, \mathrm{p}=0.003$ ). Individuals with less education may be more likely to be involved in "do-it-yourself" projects like painting rather than hiring someone else to paint 
for them. It is possible that these individuals may buy more paint than needed due to not correctly measuring the surface area to be painted (McKenzie-Mohr and Associates 2005). However, those who recycle left over paint at the event may be knowledgeable of the harmful effects of paint on the environment and may be more concerned about the environment.

Table 4. Types of Household Substances Disposed of by Participants

\begin{tabular}{|l|c|c|}
\hline Hazardous Substances & $\boldsymbol{n}$ & \% \\
\hline Paint & 99 & 68.8 \\
\hline Electronic waste & 78 & 54.2 \\
\hline Batteries & 77 & 53.5 \\
\hline Light bulbs & 62 & 43.1 \\
\hline Automotive waste & 55 & 38.2 \\
\hline Tires & 36 & 25.0 \\
\hline Television & 28 & 19.4 \\
\hline Cell phones & 19 & 13.2 \\
\hline Stereos & 14 & 9.7 \\
\hline
\end{tabular}

Source: Authors' calculations.

When participants of the event were asked about their confidence in properly managing hazardous substances, the majority felt that they were confident or very confident (Figure 1). For statistical analysis, the six confidence levels were collapsed or combined into two categories of "not confident" and "very confident". Participants who indicated a 1, 2, or 3 on their survey were identified as "not confident" and those who indicated a 4, 5, or 6 on their survey were identified as "very confident".

Figure 1. Confidence in Managing Hazardous Waste Properly

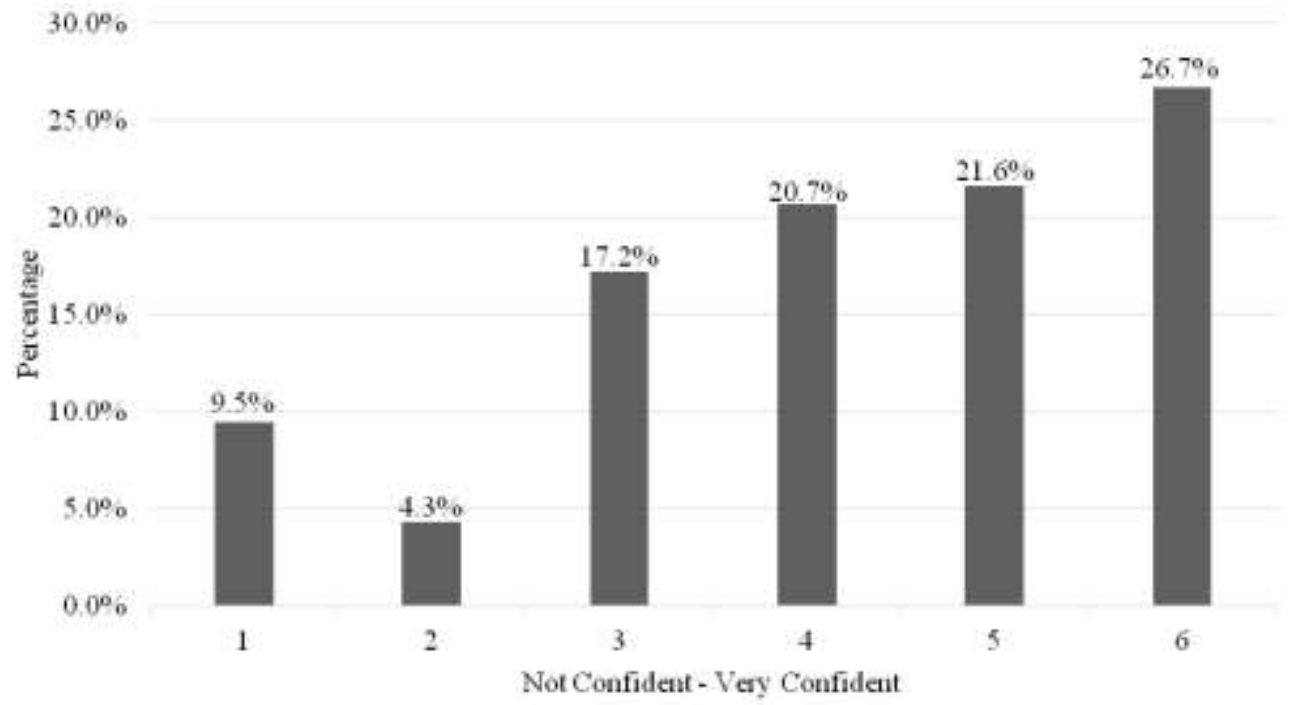

About $70 \%(n=76)$ of participants felt very confident in managing hazardous substances and $30 \%(n=33)$ felt that they were not confident. Of the $70 \%$ who felt very confident, about $71 \%(n=45)$ were males compared to about $67 \%(n=31)$ of 
females. Further statistically significant findings indicated that $78.8 \%(n=41)$ of those who were retired felt confident of knowing how to properly manage HHW compared to $62 \%(\mathrm{n}=31)$ of those who were employed $\left(X^{2}=3.5, \mathrm{df}=1, \mathrm{p}=0.049\right)$. Retired individuals may feel that they are more knowledgeable in managing HHW because of having more experience with or exposure to them over time.

The questionnaire asked participants how they found out about the Household Hazardous Recycling Day (HHWRD) event. The majority of the participants $(78.3 \%, \mathrm{n}=101)$ learned of the event by reading the newspaper, about $70 \%(\mathrm{n}=50)$ of males and $73 \%(n=38)$ of females. The majority of the individuals who participated in the event were over the age of 40 which may explain why they learned of the HHWRD event via newspapers. Older participants may be more likely to read the newspapers for information. The second most common way of learning about the event was by "word of mouth", the passing along of information through oral communication (Dictionary.com n.d.). As indicated in Figure 2, $16.3 \%(n=21)$ of participants learned of the event through this method of communication. The third most common way of learning about the event was through reading a flyer or a paper advertisement. About $9 \%(n=12)$ indicated that they learned of the event via a flyer (Figure 2).

Figure 2. Ways of Learning about the Event

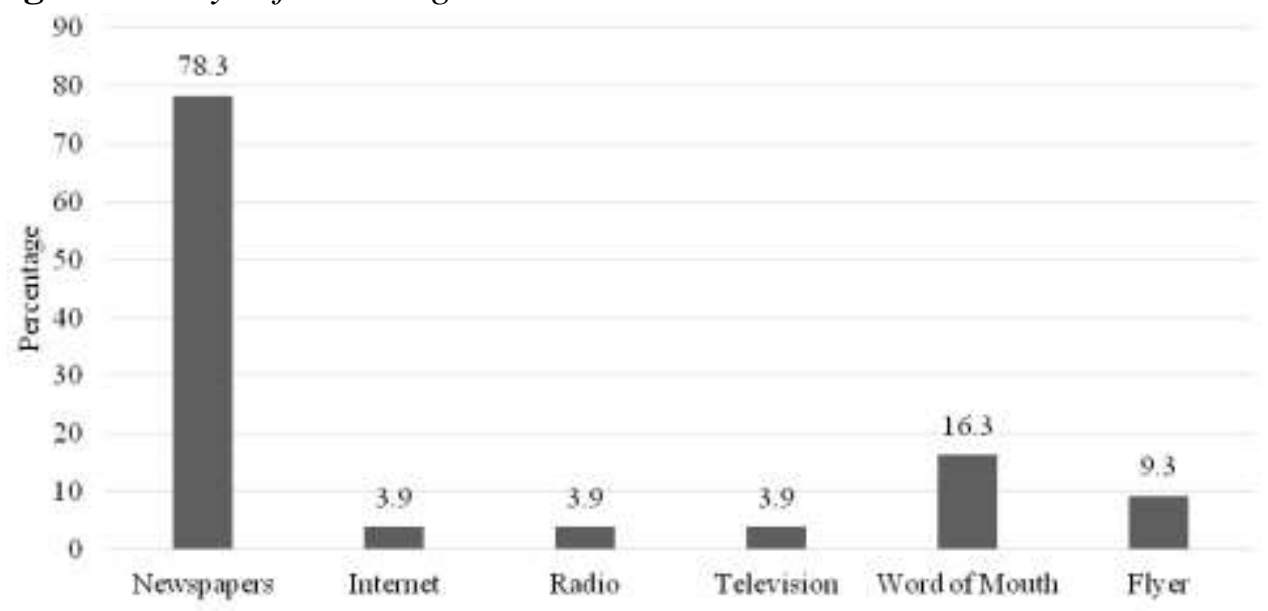

For statistical analysis, education level was collapsed or combined from seven categories into two categories. Participants who indicated having less than a college degree were collapsed into group 1 labeled "no degree" and those who had a college degree were collapsed into group 2 labeled "degree". When comparing the two collapsed education category levels, findings indicated that $20.0 \% \quad(n=10)$ of participants who did not have a degree learned about the event through "word of mouth" compared to only $8.2 \%(n=6)$ of those who did have a college degree $\left(X^{2}=3.6, \mathrm{df}=1, \mathrm{p}=0.05\right)$. This may suggest that individuals who do not have a degree may rely on or trust person-to-person communication for subjective recommendations more than those individuals who have a degree.

Since the majority of the participants were over the age of 40 years, the category of age was collapsed or combined from four categories into two categories for statistical analyses. The 20-39 age group was eliminated because of 
small numbers. Group 1 included the "40-59" age group and group 2 included participants who were 60 years old or older. When comparing the two collapsed age categories, findings indicate that $19.6 \%(n=9)$ of those who were in the "4059 " age group were more likely to find about the event through "word of mouth" than the $6.5 \%(n=5)$ of those who were over the age of $60\left(X^{2}=4.9, d f=1, p=0.03\right)$. This may suggest those in the "40-59" age group converse more at the work place than those 60 years or above who may be retired at that age.

There was also a significant difference between gender and learning about the event by a flyer. About $17 \%(n=12)$ of men found out about the event by flyer compared to about $6 \%(\mathrm{n}=3)$ of women $\left(X^{2}=3.5, \mathrm{df}=1, \mathrm{p}=0.05\right)$. This finding may suggest that men pay more attention or have a greater opportunity to see flyers or graphics placed in the workplace or community. Those in the age group "40-59" $(17.4 \%, n=8)$ were more likely to learn about the event through flyer than those who were age 60 or above $(5.2 \%, \mathrm{n}=4)\left(X^{2}=4.9, \mathrm{df}=1, \mathrm{p}=0.03\right)$. Perhaps flyers are more accessible to working individuals in the "40-59" age group than those 60 or above who are more likely to be retired. The "40-59" age group may have a greater advantage of seeing the event's flyer in their place of employment or while out in the community.

The questionnaire also asked participants about their motivation to recycle household hazardous waste. The majority $(80.9 \%, n=114)$ of the participants reported that conserving resources was one of the main motivational reasons leading to recycling household hazardous waste. Equally, males $(79 \%, \mathrm{n}=56)$ and females $(79 \%, \mathrm{n}=41)$ reported recycling HHW with the goal of conserving resources. Protection of the environment was another major motivational reason for $66 \%(n=93)$ of the participants. Of the participants, $80.8 \%(n=42)$ of females reported this reason compared to $66.2 \%(n=47)$ of men. In this study, female participants seemed to be more concerned about environmental issues than male participants.

Other motivational reasons for recycling household hazardous waste were to ensure safety and well-being within the home of the participants as well as within the community. About $51 \%(n=72)$ recycled hazardous waste because of safety concerns. Of those participants, $63.5 \%(n=33)$ were females and $47.9 \%(n=34)$ were males. Again, female participants seemed to be more concerned about safety matters than male participants. Nearly $48 \%(n=67)$ of participants indicated having been motivated to recycle household hazardous waste because of health concerns. Of those participants, $59.6 \%(n=31)$ of females recycled because of many health concerns compared to $42.3 \%(n=30)$ of males $\left(X^{2}=3.6, d f=1, p=0.043\right)$. Here as well, female participants expressed more concern about health reasons than male participants.

An additional motivational reason for the participants to recycle household hazardous waste was to get involved within the community to increase recycling rates for the City of Hammond, Louisiana (USA). About 33\% ( $n=46)$ of participants reported recycling household hazardous waste because the program is supported by the mayor and the city council. Around 35\% $(n=25)$ of males and $33 \%(\mathrm{n}=17)$ of females selected this reason. When comparing age (two categories), $40.3 \%(n=31)$ of participants 60 years and older reported involving 
themselves in this community action compared to $19.6 \%(n=9)$ of participants within the age range of 40-59 $\left(X^{2}=5.6, \mathrm{df}=1, \mathrm{p}=0.014\right)$.

When participants were asked how many events they had attended since the initial HHWRD event, $33.1 \% \quad(n=47)$ reported that it was their first time participating in the event. Approximately two-thirds of the participants were repeat visitors, visiting two or more times. Sixteen percent $(n=23)$ had visited the HHWRD event two or three times over the years. Nearly one-third of the participants $(32.4 \%, n=46)$ had attended the event four or more times (Figure 3).

Figure 3. Number of Recycling Events Attended

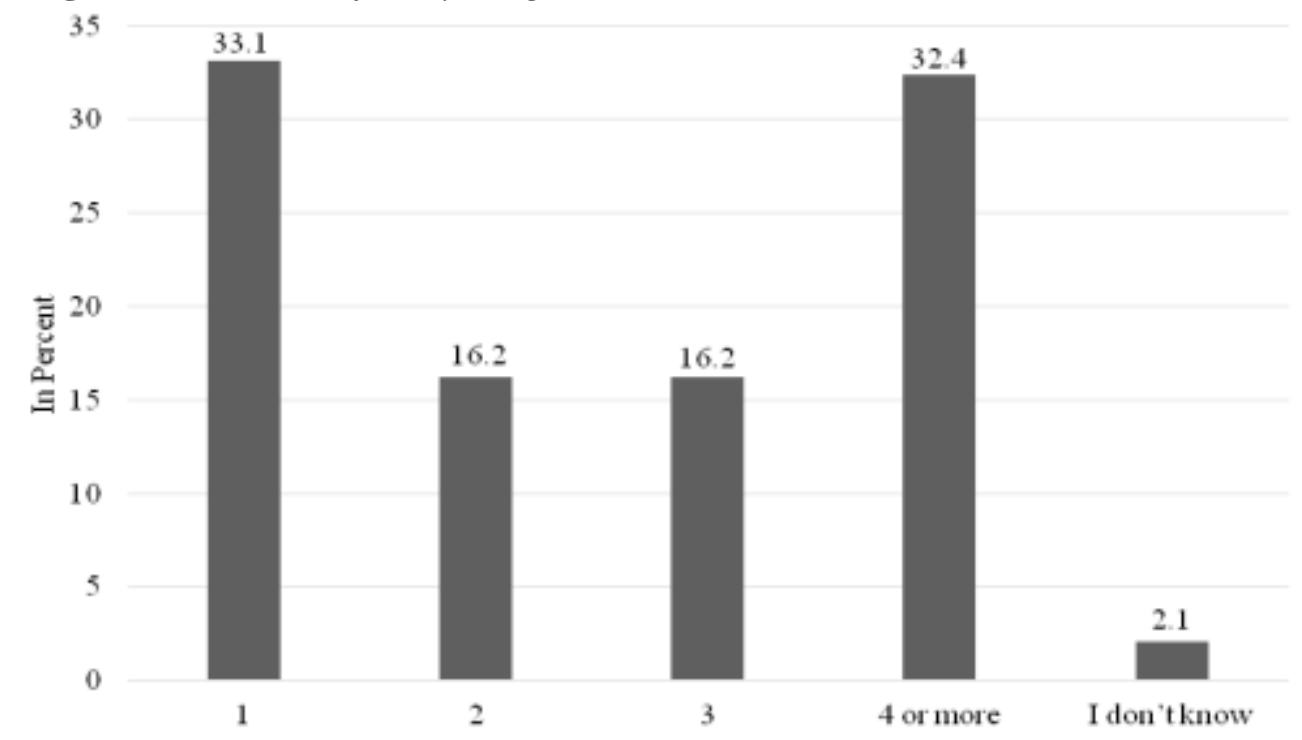

The majority of participants were repeat visitors who were returning to recycle their household hazardous waste at the HHWRD event. In addition, 60\% $(n=72)$ of participants had taken hazardous waste to the event twice a year compared to the $40 \%(n=48)$ who only had attended the event once a year. The event is normally held twice a year, in the spring and fall.

About $66 \%(n=89)$ of participants reported recycling hazardous waste from only one household. Nearly $67 \%(n=42)$ of males reported that they only recycle waste for one household compared to $72.5 \%(\mathrm{n}=37)$ of females. Almost $21 \%$ $(n=28)$ of participants reported disposing of hazardous waste from two households. Only $11.1 \%(n=15)$ of participants reported recycling household hazardous waste from more than two households, 9.5\% males $(n=6)$ and $3.9 \%$ females $(n=2)$.

Approximately 69\% $(n=99)$ of participants knew which types of household hazardous wastes were not accepted at the HHWRD event. Hazardous wastes which were not accepted included insecticides/pesticides, furniture, fire extinguishers, medicines/medical waste, Styrofoam, ink cartridges, and laboratory waste, among other materials. Appliances such as refrigerators, microwaves, stoves, washers, and dryers also were not accepted as well as radioactive devices or materials including smoke/fire detectors. Non-residential waste also was not accepted. 
For the items that were not accepted, 34\% $(n=44)$ reported that they do "nothing" with the items. The remainder of the participants reported that they throw the items away or otherwise send it to landfills. Of the participants in the study, $31 \%(n=44)$ were not sure what materials were not accepted. Items that were accepted at the event other than items previously listed included paper, plastic, glass, cleaning solvents, polishes, lighter fluid, aerosol cans, moth balls and small propane bottles.

The questionnaire asked participants if there should be a fee charged for recycling household hazardous substances. The majority of participants $(82 \%$, $\mathrm{n}=103$ ) felt that the community should not have to pay a fee to recycle. The remaining $18 \%(n=23)$ felt that a small disposal fee or donation could be charged. Approximately $97 \%(n=31)$ of the participants who thought a fee should be charged felt that a fee of $\$ 10$ or less would be feasible. Only 3\% $(n=1)$ of participants felt that a fee of over $\$ 10$ would be feasible. Participants may feel that they should not have to pay to dispose of their hazardous waste because companies created the wastes and are also benefiting from materials that are recycled. Recycling efforts can result in companies saving energy and materials which in turn saves them money. Others may feel that tax dollars pay for recycling programs. In the collection of recyclables, the materials collected can help to pay for the program.

\section{Conclusions}

As household hazardous waste continues to grow in the City of Hammond, Louisiana (USA) as well as throughout the United States and in other countries, recycling programs like the Household Hazardous Waste Recycling Day event is a positive start in resolving the issue of hazardous waste and pollution. Recycling events which involve community participation are necessary in order to bring change within a community. Such events may influence members of the community to become proactive and to develop a positive attitude toward recycling household hazardous waste. By developing such programs in other parts of the world, community members may begin to change their recycling attitudes, habits, and behaviors. Hopefully, over time citizens in the United States and other parts of the world may eventually be able to eliminate household hazardous waste.

The Household Hazardous Waste Recycling Day event brings awareness to the citizens of Hammond, Louisiana and surrounding cities. Finding ways to educate a community on the topic of the 3 Rs (reduce, reuse, recycle) is very important in achieving desired outcomes. Becoming knowledgeable about hazardous waste and how it affects humans and the environment is the first step in achieving a common goal for the community. Learning the skills necessary to change recycling attitudes, habits and behaviors is the second step in achieving desired outcomes within the community. Assisting and sustaining behavior change is the third important step. Once the community as a whole maintains the ability to reduce, reuse and recycle household hazardous waste, positive environmental and health outcomes may develop. Starting educational 
efforts now within any community could greatly increase the chances of maintaining these skills in generations to come.

Recycling behavior depends on several factors. These factors include but are not limited to an individual's attitude toward recycling, peer influences, family background, beliefs, and environmental awareness, among other factors (Garces et al. 2002, Bezzina and Dimech 2011). For example, a person who is socially surrounded by recyclers is more likely to recycle waste. In addition, an individual who shows concern for the environment is more likely to recycle waste. Generally, positive attitudes and positive social influences towards recycling indicates a stronger intent regarding recycling (Bezzina and Dimech 2011). In this study, participants were motivated to recycle household hazardous waste because of their concerns about conserving resources and attending to environmental and safety issues.

Incentives as well as barriers may affect how an individual perceives recycling (Garces et al. 2002, Bezzina and Dimech 2011). It is important to assist in removing barriers. There are several factors that may hinder a person from recycling. Many individuals view recycling as an inconvenience. Lack of time and space could be viewed as two of the biggest inconveniences associated with recycling (Bezzina and Dimech 2011). Many individuals feel that they do not have the time to separate the recyclables from trash and once separated they do not have the space to store the recyclables until they are able to make a deposit. Finding time to make a deposit at a recycling center is another time restraint. In addition, not having enough recycling centers or poorly located ones are considered other inconveniences (Bezzina and Dimech 2011). Others may find it difficult to transport the recyclables or may not have the proper transportation. Finally, lack of knowledge is also considered a barrier (Yepsen 2007). In this particular study, the recycling site was located in the center of the city. Participants who lived within the city limits would only have to travel a maximum of five miles to deposit hazardous waste. Most individuals had already participated in previous events which suggests that they do not mind traveling the distance.

Demographics may also influence recycling behaviors. In this study as well as others, findings suggest that men are more likely to recycle than women (Bezzina and Dimech 2011, Pakpour et al. 2013). However, other studies suggest that women are more likely to recycle than men (Aung and Arias 2006, Davis et al. 2009). In this study and Pakpour et al. (2013), findings suggest that those who had a college degree were more likely to recycle household hazardous waste; however Bezzina and Dimech (2011) found that educational level is a not a factor. Finally, this study and Pakpour et al. (2013) suggest that older participants are more likely to recycle yet Bezzina and Dimech (2011) reported that age may not have an impact.

Becoming educated and educating the community is very important when it comes to knowing what is hazardous and correctly managing hazardous substances. Some do not know that many of the products they use are made from chemicals or that they are hazardous substances. In order to continue to have successful programs such as the Household Hazardous Waste Recycling 
Day event, we must continue to raise awareness about hazardous substances and their harmful effects. Hosting community fairs and handing out educational pamphlets can help inform participants of the importance of recycling hazardous waste.

Improving the HHWRD event may increase participation city and parishwide (county) levels. One recommendation for the program includes increasing how often the event occurs as well as increasing the hours of each event. Another recommendation is to extend services including "pick up" services for those who may not be able to attend the event. Offering incentives can also increase the events' overall participation. Monetary incentives as well as offering participants a reward may also increase active participation within the community (Garces et al. 2002, Bezzina and Dimech 2011). Partnering with local restaurants to provide "food coupons" for free food or gift cards may spark the interest of community members in becoming more active in community hazardous recycling programs.

\section{References}

Aung M, Arias ML (2006) Examining waste management in San Pablo del Lago, Ecuador: A behavioural framework. Management of Environmental Quality: An International Journal 176: 740-752.

Bezzina FH, Dimech S (2011) Investigating the determinants of recycling behavior in Malta. Management of Environmental Quality: An International Journal 22: 463485.

Davis G, O'Callaghan F, Knox K (2009) Sustainable attitudes and behaviours amongst a sample of non-academic staff- a case study from an Information Services Department, Griffith University, Brisbane. International Journal of Sustainability in Higher Education 10(2): 136-151.

Dictionary.com. (n.d.) Word of mouth. Retrieved from http://goo.gl/HFSdNC. [Accessed: 13 May 2014]

EPA - United States Environmental Protection Agency (2011) Hazardous substances and hazardous waste. Retrieved from http://goo.gl/Rb9C46.

EPA - United States Environmental Protection Agency (2013) Characteristic wastes. Retrieved from http://goo.gl/m3s5D2.

EPA - United States Environmental Protection Agency (2014a) Common waste and materials. Retrieved from http://goo.gl/qjV8fS.

EPA - United States Environmental Protection Agency (2014b) Municipal solid waste generation, recycling and disposal in the United States: Facts and figures of 2012. Retrieved from http://goo.gl/GCJKw9.

Garces C, Lafuente A, Pedraja M, Rivera P (2002) Urban waste recycling behavior: Antecedents of participation in a selective collection program. Environmental Management 30: 378-390.

Hoornweg D, Bhada-Tata P (2012) What a waste: A global review of solid waste management. The World Bank. March 2012 (15). Retrieved from http://goo.gl/Qya2f.

LDEQ - Louisiana Department of Environmental Quality (2011) 2011 Solid waste capacity report. Retrieved from http://goo.gl/6oTsh. 
Vol. 4, No.2 McCoy et al.: Characteristics of Community Members who Recycle...

LDEQ - Louisiana Department of Environmental Quality (2013) Summary of 2012 annual recycling reports. Retrieved from http://goo.gl/7dpHPe.

Massawe E, Legleu T, Vasut L, Brandon K, Shelden G (2014) Voluntary approaches to solid waste management in small towns: A case study of community involvement in household hazardous waste recycling. Journal of Environmental Health 76(10): 26-33.

McKenzie-Mohr and Associates (2005) Residential paint survey: Report and recommendations. Retrieved from http://goo.gl/jsfNtW.

NIH - United States National Library of Medicine, National Institutes of Health (2012) Hazardous materials. Retrieved from http://goo.gl/Y5YhAo.

Pakpour AH, Zeidi IM, Emamjomeh MM, Asefzaden S, Pearson H (2014) Household waste behaviours among a community sample in Iran: An application of the theory of planned behaviour. Waste Management 34(6): 980-986.

Yepsen R (2007) Encouraging sustainable recycling behavior through financial incentives. Biocycle 48: 34-37. 